\title{
Skewing angle magnet and coil reduced starting torque in a permanent magnet synchronous generator for a small vertical axis wind turbine
}

Priwan Pongwan ${ }^{1}$, Kusumal Chalermnayanont ${ }^{2}$, Mintra Trongtorkarn ${ }^{3}$, Suppachai Jina ${ }^{1}$,

5 Montri Luengchavanon ${ }^{4 *}$

${ }^{1}$ Energy Technology Program, Faculty of Engineering, Prince of Songkla University, Hatyai, Songkhla 90110 Thailand.

${ }^{2}$ Department of Electrical Engineering, Faculty of Engineering, Prince of Songkla University, Hatyai, Songkhla 90110 Thailand.

$10{ }^{3}$ Department of Industrial Electrical Technology, Faculty of Science and Technology, Suratthani Rajabhat University, Suratthani 84100, Thailand.

4* Sustainable Energy Management Program, Faculty of Environmental Management, Prince of Songkla University, Hatyai, Songkhla 90110 Thailand.

Correspondence to: Montri Luengchavanon (montri.su@psu.ac.th)

Abstract. This work investigated the effects of changing the skewing angle of a magnet coil on starting torque in a permanent magnet generator (PMSG) fitted in a low speed vertical wind turbine. The optimal skew angle of the magnet-coil was found to be 15-0 (degrees), generating $1.22(\mathrm{~N}-\mathrm{m})$ starting torque and 295.40 (W) compared with a skew angle of 0-0 (degrees). This skew angle reduced starting torque and power by $5.43 \%$ and $1.96 \%$, respectively. A Savonius and H-Darrieus stacked turbine blade operated at a wind speed of $1.90 \mathrm{~m} / \mathrm{s}$ and $1.31 \mathrm{~N}-\mathrm{m}$ torque. This blade was used in a fully operational vertical wind turbine, was connected to the PMSG that can cut-in speed of $2.1 \mathrm{~m} / \mathrm{s}$. It was concluded that a $15-0$ (degree) skewing angle magnet-coil can be applied to a low speed vertical wind turbine.

\section{Introduction}

Wind energy is a relatively inexpensive renewable energy resource, which can be widely distributed. In particular, due to the available space and wind currents, ocean environmental conditions provide a suitable location to harness wind energy. In Europe, offshore wind energy is continuously being developed, with net offshore wind energy power capacity (2649 MW) and cumulative offshore wind capacity (approx. 18,499MW) reported to have increased in 2018 (Walsh, 2019). 
Bloomberg New Energy Finance have suggested that the global offshore wind market will approach a cumulative capacity of $115 \mathrm{GW}$, with a 16\% annual growth rate from 2017 to 2030 (Jiang et al., 2020). Therefore, the development of cost effective megawatt wind turbines are likely to become more popular across Europe and Asia, with costs likely to be reduced via two methods. In utilizing future offshore wind energy, the vertical axis wind turbine (VAWT) is expected to perform better than the horizontal axis wind turbine (HAWT). This is because the VAWT has a lower center of gravity and simple mechanical structure, which is easy to fabricate, and requires low maintenance. Moreover, the VAWT has a high potential to be scaled to a number of different sizes (Paquette and Barone, 2012).

In order to meet commercialization requirements, VAWT technology is constantly improving. Due to its unique rotating motion, the hardness of the VAWT blade provides the greatest amount of wind power on the upwind half circumference, however it provides a lower power coefficient compared with HAWT (Liu et al., 2019). This has led to several investigators exploring ways to improve the power output of isolated wind turbines by optimising and developing variable pitch technology or air-foils. The power coefficient can be improved by harnessing more wind energy via auxiliary devices, such as deflectors and diffusers (Takao et al., 2009; Wong et al., 2018;Malipeddi and Chatterjee, 2012). The design of new guide vane geometry for a VAWT has been shown to improve power with high tip speed ratios (Takao et al., 2009). The diffuser structure around a VAWT allows for an increased power coefficient and more energy from wind turbines positioned adjacent to each other (a wind turbine array) providing a new approach to improve the power output of VAWT's (Dabiri, 2011).

The electrical generator is the main device of wind turbine technology, and assists with providing higher efficiency. Presently, more than $90 \%$ of wind power plants have an electrical power range between $0.1-20 \mathrm{~kW}$, and are often used in permanent magnet synchronous generators (PMSG) (Soderlund et al., 1996). As these wind power plant generators are driven directly from the shaft of wind turbine using no reduction gear (Haring et al., 2003), low speed generators can sufficiently provide a large number of poles on the rotor, with a relatively small pole pitch (Cistelecan et al., 2007). However, there are a number of technological problems related to stator generator production, and the automatically generated process of the threephase $(m=3)$ fabricated winding insertion. Therefore, the application of generators, which use windings with a number of poles on poles and phase $\mathrm{q}=1$, can be limited. The relationship between pole pair number $p$ and gear teeth number $Z_{l}$ is defined in Equation (1) (Germar et al., 2012).

$$
Z_{1}=2 p m q
$$

Where $m$ is number of phases, and $q$ is number of teeth on the pole and phase. When the phase is $q=1$, the system needs 6 teeth divisions to enable the winding to settle down on one rotor's polar branch. The increased attention to the winding possessing sufficient length, with overlapping frontal connections, has led to an increase in growth, with an increase in copper consumption and eddy current losses. This is a disadvantage, has it has led to a synchronous generator with non-overlapping concentration windings for wind power (Saavedra et al., 2014;Levin et al., 2012;Magnussen and Sadarangani, 2003). Based on the PMSG generator producing high starting torque values, and a dependency of the torque to be related to the rotor's rotation angle (Bakiev et al., 2018). The skewing ways of a permanent magnet machine can improve starting torque, by 
affecting the torque and air-gap flux shape. However, the starting torque can also be reduced when the electrical power is decreased (Lateb et al., 2006), leading to a compromise with the skewing technique when it is applied to small wind turbines.

This study investigated the angle of skewing magnet-coils for reducing starting torque and electrical power in a PMSG. The optimal angle of the skewing magnet-coil was applied to a vertical wind turbine to validate the operation of a low speed vertical wind turbine at $2 \mathrm{~m} / \mathrm{s}$.

\section{Experiments}

In order to conduct the experiments of this investigation, a suitable test environment was arranged, including obtaining a laboratory machine. The acrylic plate was automatically changed to adjust the skewing angle to support the magnets and coils at 0-0, 0-5, 0-10, 0-15, 5-0, 5-5, 5-10, 5-15, 10-0, 10-5, 10-10, 10-15, 15-0, 15-5, 15-10, 15-15 degrees, respectively; as shown in Figure 1. The testing station was conducted in two parts, firstly, the controller and PMSG were used for the 3 phase inverter (1.5 kW/220 Vac, Input: $220 \mathrm{Vac}$, Output: $380 \mathrm{Vac}$, Jaden) in order to vary the speeds of $3 \mathrm{hp}$ motors $(0.78 \mathrm{~kW}$, VEB elektromotorenwerk). The PMSG was then conducted with 12 magnets $(\mathrm{NdFeB})$, which were used to skew the angles (sizes was 100x20x5 mm: $251 \mathrm{mT}$ ) that were installed onto the acrylic disc (size: 400x10 mm) for the rotor section. The 9 coils (size was $100 \times 70 \times 12 \mathrm{~cm})$ and air core $(2 \times 3.5 \times 2 \mathrm{~cm})$ were installed onto the acrylic disc (size: $400 \times 10 \mathrm{~mm})$ for the stator section, and the PMSG was used with a $2 \mathrm{~mm}$ air-gap (Figure 2 and Table 1). Secondly, the measurement instruments included a torque meter (BCM sensor technologies, Model: 1811, Cap: 500 Nm, Accuracy (torque): 0.5\% fs, Supply: \pm 15 Vdc, Max:

80 speed $7000 \mathrm{rpm}$, Load current $<10 \mathrm{~mA}$ ), and a power measurement, using a 3 phase Power \& Harmonic Analyzer (Chauvin Arnoux: CA8331). The PMSG output was connected to a 3 phase switch and variable $300 \mathrm{~W}$ resistance load.

Table 1. The PMSG parameters

\begin{tabular}{|l|c|l|}
\hline \multicolumn{1}{|c|}{ Constructive elements } & value & \multicolumn{1}{|c|}{ Unit } \\
\hline Number of phase & 3 & - \\
\hline Number of pole (P) & 12 & - \\
\hline Number of stator slots & 9 & - \\
\hline Flux density of NbFeB Magnet & 251 & $\mathrm{mT}$ \\
\hline Magnet length & $100 \times 20 \times 12$ & $\mathrm{~mm}$ \\
\hline Coil length & $100 \times 70 \times 12$ & $\mathrm{~mm}$ \\
\hline Number of coils & 2700 & $\mathrm{~N} / \mathrm{Ph} a \mathrm{se}$ \\
\hline Rotor outer diameter & 400 & $\mathrm{~mm}$ \\
\hline Stator outer diameter & 400 & $\mathrm{~mm}$ \\
\hline Air gap & 3 & $\mathrm{~mm}$ \\
\hline
\end{tabular}



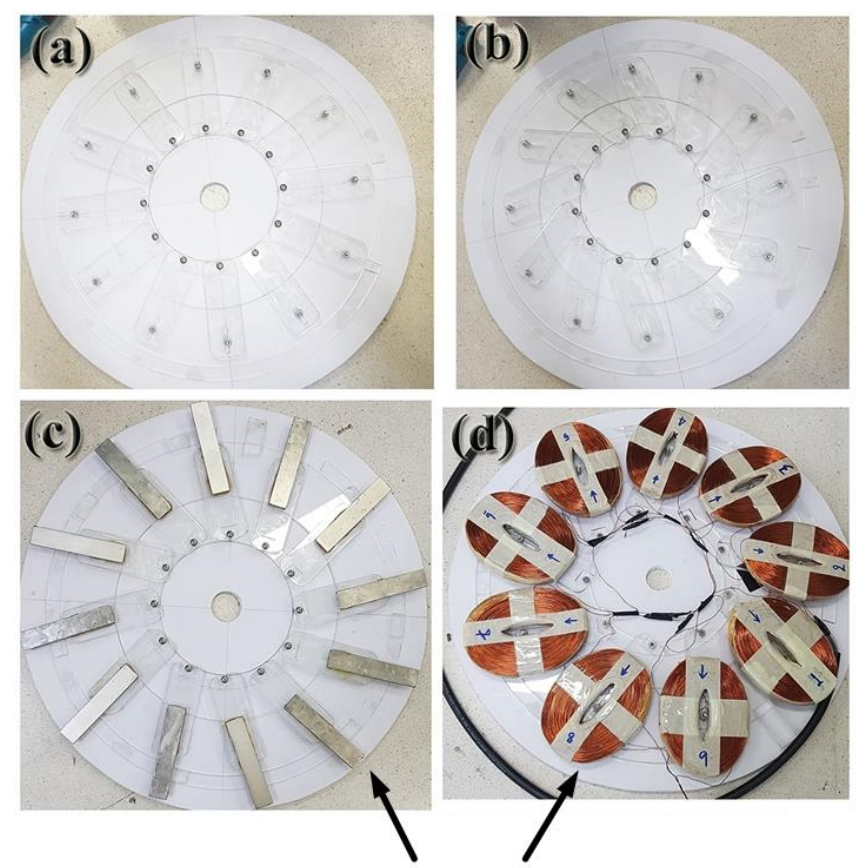

Skewing angle magnet-coil (Degree)

85 Figure 1: (a) the acrylic plate for automatically skewing the angle of the magnets; (b) the acrylic plate can automatically skew the angle of the coils; (c) the 12 magnets installed on the acrylic disc for the rotor section; (d) 9 coils installed on the acrylic disc for the stator section.

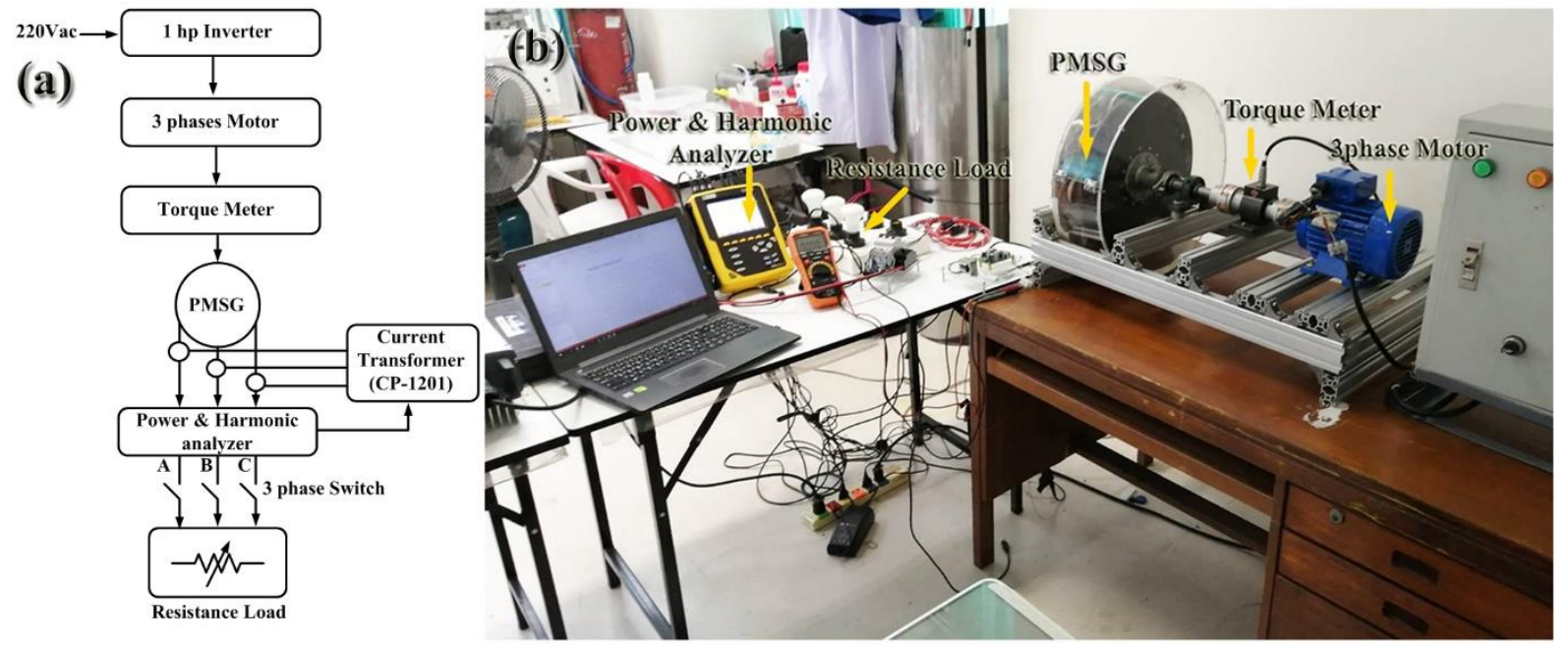

Figure 2: (a) Diagram showing the measurement of the Permanent Magnet Synchronous Generator (PMSG) connected to the motor driver and electrical load; (b) the PMSG experimental testing station. 


\section{Results and discussion}

Fig 3 (a) shows the comparison of the output torque with the skewing angle magnets-coils under no-load conditions.

95 The trends fluctuated, with torque ranging between $0.05-0.30 \mathrm{~N}-\mathrm{m}$. The skewing angle of the magnets-coils could not exactly indicate a reduced torque. Fig 3 (b) shows the comparison of the output torque with the skewing angle magnets-coils under on load conditions. The trends indicated that the transient torque was related to the time duration and the skewing angle of the magnets-coils. The starting torque was increased from 0.20 to $1.4 \mathrm{~N}$-m over 2.5 seconds, however after 4 seconds, the generated torque remained constant, with the behavior of each trend dependent on the skewing angle of the magnets-coils. The PMSG was connected to the electrical load that fabricated the induction of power between the magnets and coils. It was found that the trends between on load and no load were different, with the PMSG generating power induction between the magnets and coils when operated with no load. The electricity transferred from coils (stator) without load has previously been shown to fluctuate the signal (Bülow et al., 2012). In addition, the starting torque partly depends on the load, which breaks the torque produced on the rotor's rotation angle (Ose-Zala et al., 2014). These starting torques could be fabricated over 2.5 seconds.
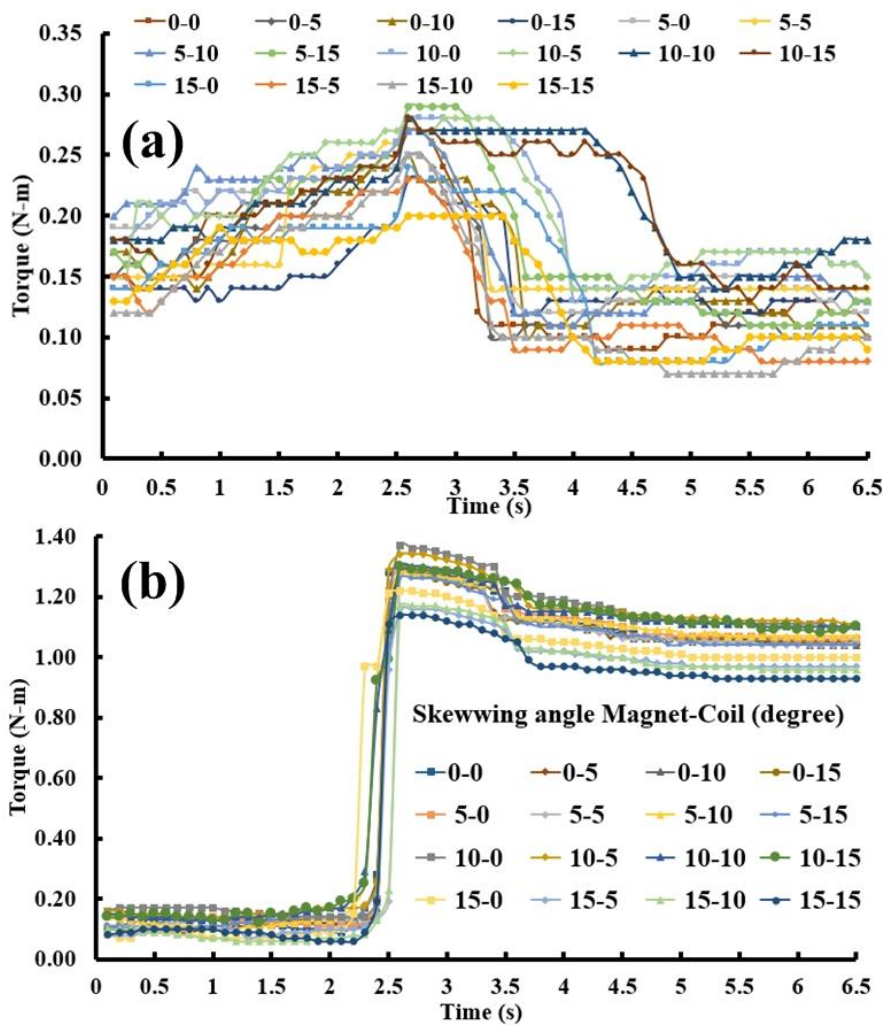

Figure 3: The behavior of PMSG based on starting torque (a) the transient starting torque of PMSG no-load conditions, (b) the transient starting torque of PMSG with 300W electrical load. 


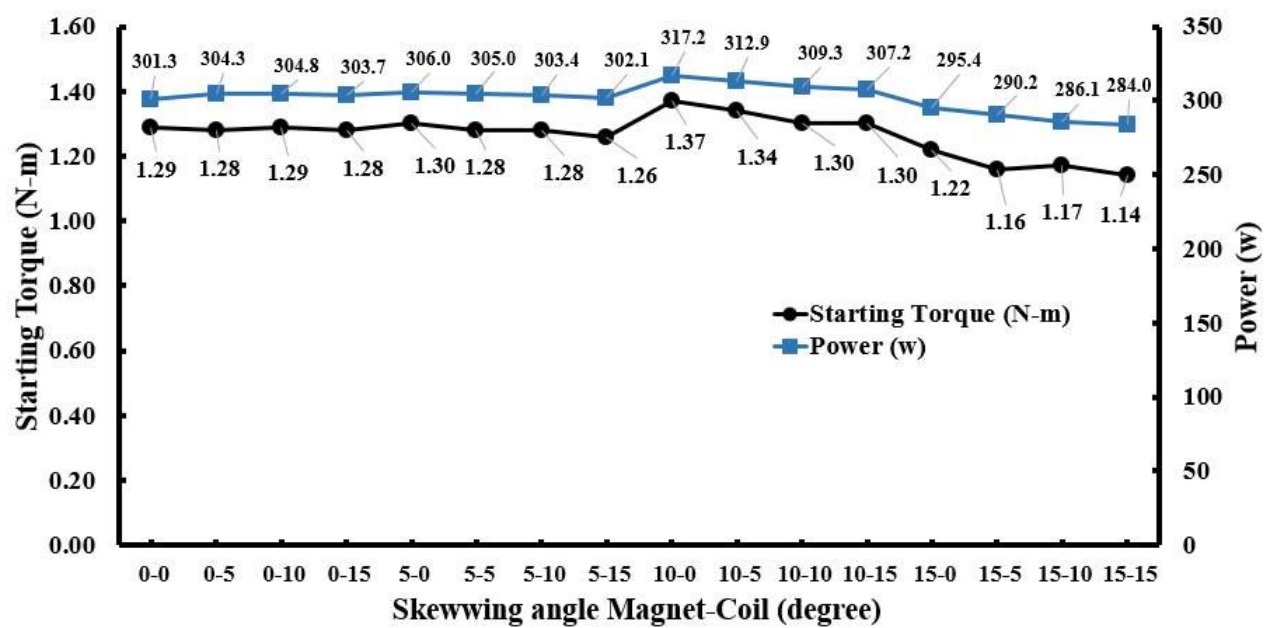

Figure 4: The relationship between starting torque $(\mathrm{N}-\mathrm{m})$ and skewing angle magnet-coil (degree) which compared maximum starting torque and electrical power.

Fig 4 shows comparison values between the starting torque and power when changing the skewing angle magnet-

115 coils in the PMSG generator. In the control condition, it was determined that the skewing angle magnet-coil at 0-0 generated $1.29 \mathrm{~N}-\mathrm{m}$ and $301.3 \mathrm{~W}$ compared with other conditions. The skewing angle magnet-coil at $0-5,0-10,0-15,5-0,5-5,5-10,5-$ 15 degrees provided similar starting torque and power values to 0-0 degrees. In contrast, the skewing angle of the magnet-coil at 10-0, 10-5, 10-10, 10-15, 15-0, 15-5, 15-10 and 15-15 degrees indicated that 10-0 degree produced a higher starting torque $(1.37 \mathrm{~N}-\mathrm{m})$ and power $(317.2 \mathrm{~W})$, respectively, with both parameters gently decreasing until 15-15 degree. In particular,

120 starting torque at a skewing angle of 15-0 (1.22 N-m), 15-5 (1.16 N-m), 15-10 (1.17 N-m) and 15-15 degrees $(1.14 \mathrm{~N}-\mathrm{m})$, were lower than the 0-0 degree condition. These conditions are applicable to a wind turbine.

The starting torque $\left(T_{\text {starting }}\right)$ can be fabricated by estimating the energy in the air-gap by stepping the rotor. The energy changed in the PMSG generator and iron is minimal when compared to the air (Eom et al., 2001).

$$
T_{\text {starting }}(\theta) \approx-\frac{\partial W_{\text {air }-g a p}(\theta)}{\partial \theta}=-\frac{1}{2} \emptyset_{g}^{2} \frac{d R}{d \theta}
$$

125 Where $W_{\text {air-gap }}(\theta)$ is energy within the air-gap, $\phi_{g}$ is the air flux between magnet and coil, $\theta$ is rotor angular position in electrical degrees and $R$ is the air-gap reluctance. Eq (1) can be expressed in component form for a radial flux permanent magnets (RFPM) generator (Eom et al., 2001), the $\phi_{g}$ is the main factor that affected to the skewing angle magnet-coil. Eq (2) can be expressed in the air flux from the magnet to coil (Wirtayasa et al., 2017).

$$
\emptyset_{g}=\frac{2}{\pi} B_{m g} \frac{\pi}{2 p}\left(R_{\text {out }}^{2}-R_{\text {in }}^{2}\right)
$$

130 Where $B_{m g}$ is flux density from magnet, $2 P$ is the number of poles, $R_{\text {in }}$ and $R_{\text {out }}$ are the radial radius of the permanent magnet at the inner and outer diameter. Therefore, the skewing angle magnet-coil can be affected from the area of $\phi_{g}, R_{\text {in }}$ and $R_{\text {out }}$ by increasing or decreasing the starting torque ( $\left.T_{\text {starting }}\right)$ in the PMSG; as shown in Fig 5. Additionally, the skewing angle magnet- 
coil is also affected by the electrical power $\left(P_{\text {out }}\right)$ of the PMSG, causing a change in the voltage (rms) value of the $\mathrm{E}_{\mathrm{EMF}}$ in the PMSG; as shown in Eq (3-4-5).

135

$$
\begin{gathered}
k_{w 1}=k_{d 1} k_{p 1} k_{s n 1} \\
E_{E M F}=\pi \sqrt{2} f N_{1} k_{w 1} \emptyset_{g} \\
P_{\text {out }}=\frac{E_{E M F}^{2}}{\left(R_{m}+R_{L}\right)^{2}+X_{S}^{2}} R_{L}
\end{gathered}
$$

Where $k_{w l}$ is the winding factor of the coil, $k_{d l}$ is the distribution factor, $k_{s n l}$ is the skew factor, $f$ is frequency, $N_{l}$ is

140 the number of armature turns in one phase, $R_{m}$ is the armature resistance, $R_{L}$ is load resistance, and $X_{S}$ is the synchronous reactance. Based on $\mathbf{E q}(\mathbf{3})$ is represented that the $k_{w l}$ is affected from the shape and winding of the coil. While $k_{s n l}$ is the main factor, which changed starting torque and power when skewing the angle magnet-coil.
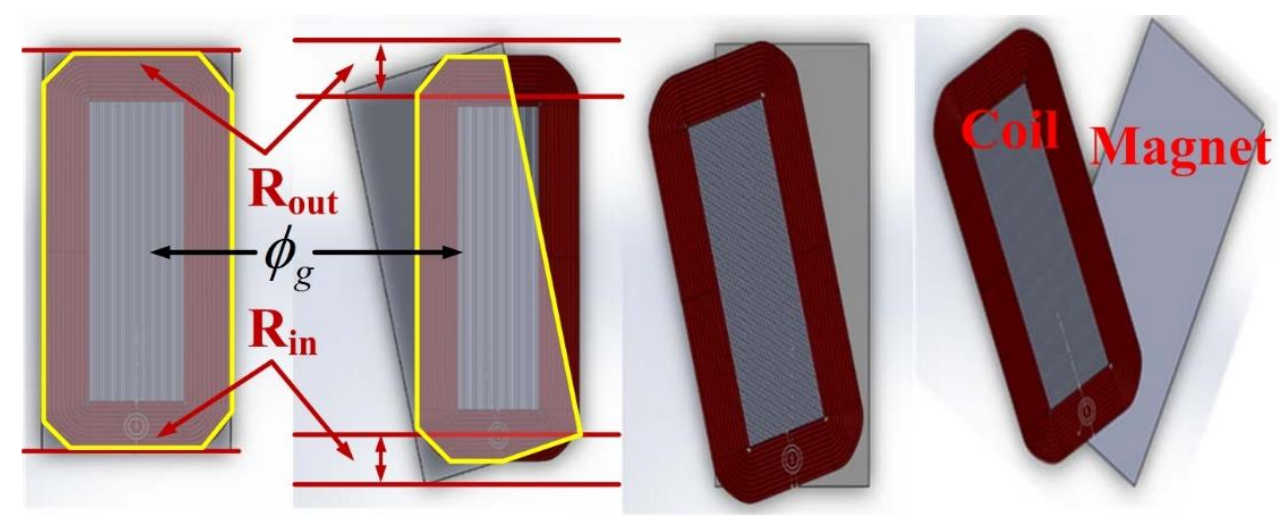

145 Figure 5: The skewing angle magnet-coil affected the air flux between the magnet and coil and radial radius of the permanent magnet at the $\left(\mathrm{R}_{\text {in }}\right)$ inner and $\left(\mathrm{R}_{\text {out }}\right)$ outer diameter.

(Suppachai et al., 2019 ) reported that the Savonius and H-Darrieus blade, which are stacked together, can operate at 10kWwind turbine; as shown in Figure 6. Table 1 shows the characteristics under these conditions for selecting the optimal skewing angle of the magnet-coil condition, and the properties of the blade are shown in Figure 7. In order to initiate the first turn of the wind turbine, it was determined that the torque of the blade must be higher than the starting torque from the PMSG generator, with the wind turbine requiring to cut-in at approximately $2 \mathrm{~m} / \mathrm{s}$ condition. The blade can be focused to a wind speed of $1.90 \mathrm{~m} / \mathrm{s}$ and $1.31 \mathrm{~N}-\mathrm{m}$ to be matched with the starting torque of the PMSG generator. The skewing angle magnet is easier to fabricate compared with skewing angle coil for the PMSG generator (Bianchi and Bolognani, 2002). However, since the PMSG generator requires a high power with a reduced starting torque, an optimal skewing angle magnet-coil of 15-0 degrees enables the production of $1.22 \mathrm{~N}-\mathrm{m}$ and $295.40 \mathrm{~W}$, to reduce starting torque (5.43\%) and power (1.96\%), respectively. 
The connection of the blade and PMSG generator, which allows the wind turbine to cut-in at low speed wind, $J_{\text {cut-in }}$ (equivalent inertia) is shown in Eq (6) (Belmili et al., 2017; Hsieh et al., 2009).

$$
J_{\text {Cut-in }}=T_{\text {blade }}-T_{\text {starting }}
$$

160

Where $T_{\text {blade }}$ is torque from the blade of the turbine (Table 2). The cut-in of this vertical wind turbine cannot start turning at $1.90 \mathrm{~m} / \mathrm{s}$ wind speed due to the systems combined force of $T_{\text {starting. }}$. Hence, the real operation of this vertical wind turbine system can be cut-in at $2.1 \mathrm{~m} / \mathrm{s}$.

Table 2: The comparison of parameters between the PMSG generator and Savonius and H-Darrieus blade, which were stacked together for selected the skewing angle magnet-coil condition.

\begin{tabular}{|c|c|c|c|c|}
\hline $\begin{array}{c}\text { PMSG generator As shown } \\
\text { in Figure 2 }\end{array}$ & \multicolumn{5}{|c|}{ Parameters } \\
\hline Starting Torque (N-m) & $\begin{array}{c}\text { Skewing angle } \\
\text { magnet-coil } \\
\text { (Degree) }\end{array}$ & $\begin{array}{c}\text { Electrical } \\
\text { Power (W) }\end{array}$ & $\begin{array}{c}\text { \% Reduced } \\
\text { starting torque }\end{array}$ & $\begin{array}{c}\text { \% Reduced } \\
\text { power }\end{array}$ \\
\hline 1.29 & $0-0$ & 301.30 & - & - \\
\hline $\mathbf{1 . 2 2}$ & $\mathbf{1 5 - 0}$ & $\mathbf{2 9 5 . 4 0}$ & $\mathbf{5 . 4 3}$ & $\mathbf{1 . 9 6}$ \\
\hline 1.16 & $15-5$ & 290.20 & 10.08 & 3.68 \\
\hline 1.17 & $15-10$ & 286.10 & 9.30 & 5.04 \\
\hline 1.14 & $15-15$ & 284.00 & 11.63 & 5.74 \\
\hline $\begin{array}{c}\text { Blade of Savonius and H- } \\
\text { Darrieus stacked together } \\
\text { as shown in Figure 6 (a) } \\
\text { and Figure 7 }\end{array}$ & & & & \\
\hline Torque (N-m) & Wind Speed & - & & - \\
\hline 0.22 & $(\mathrm{~m} / \mathrm{s})$ & & - & - \\
\hline 0.46 & 1.52 & - & - & - \\
\hline 0.98 & 1.60 & - & - & - \\
\hline $\mathbf{1 . 3 1}$ & 1.75 & - & - & - \\
\hline
\end{tabular}

Figure 8 shows the comparison of the 0-0 and 15-0 degrees skewing angle magnet-coil conditions, based on the relationship of the power and rotation speed. The skewing angle magnet-coil at 15-0 degrees was selected for using in the PMSG generator. The results indicated that $15-0$ degrees could gently decrease power by $1.50 \%$ power at $25-650 \mathrm{rpm}$ compared with the $0-0$ degrees condition. 
https://doi.org/10.5194/wes-2020-101

Preprint. Discussion started: 25 November 2020

(c) Author(s) 2020. CC BY 4.0 License.

(c) (i)

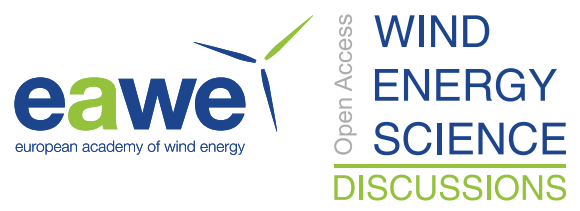

175

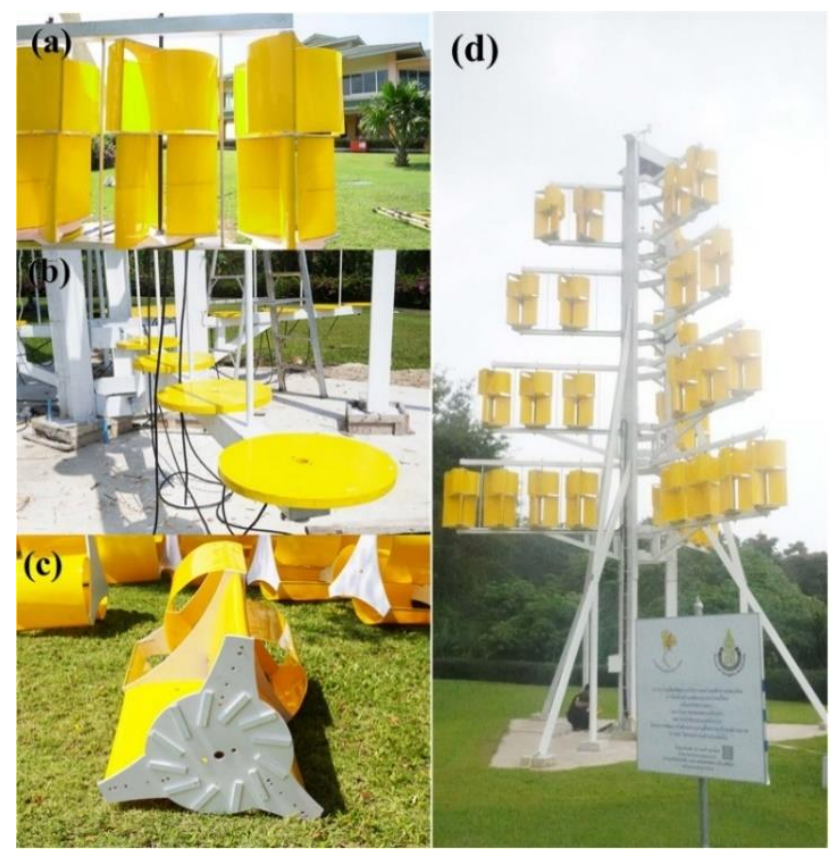

Figure 6: The $300 \mathrm{~W}$ (per turbine) vertical wind turbine installed at Rajjaprabha dam, Thailand (a) the blade of the vertical wind turbine (b) the stator of the PMSG generator (c) the rotor of the PMSG generator used in the skewing angle magnet-coil at 15-0 degree (d). 10kW wind tree combined with a 32 wind turbine (Suppachai et al., 2019 ).

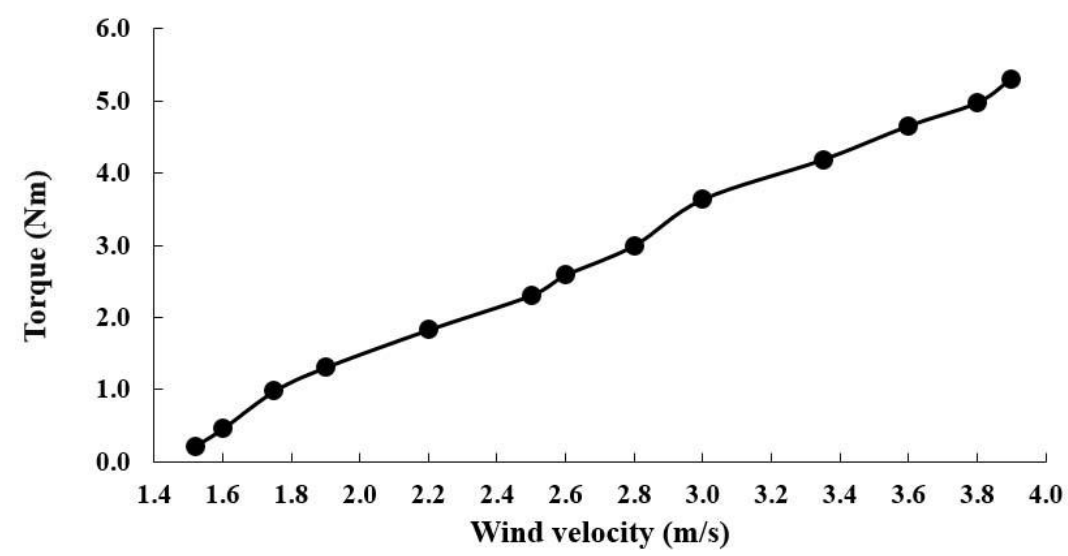

Figure 7: The relationship between the torque and wind speed of of the Savonius and H-Darrieus stacked blade, which is represented in Figure 6 (a) (Suppachai et al., 2019 ). 


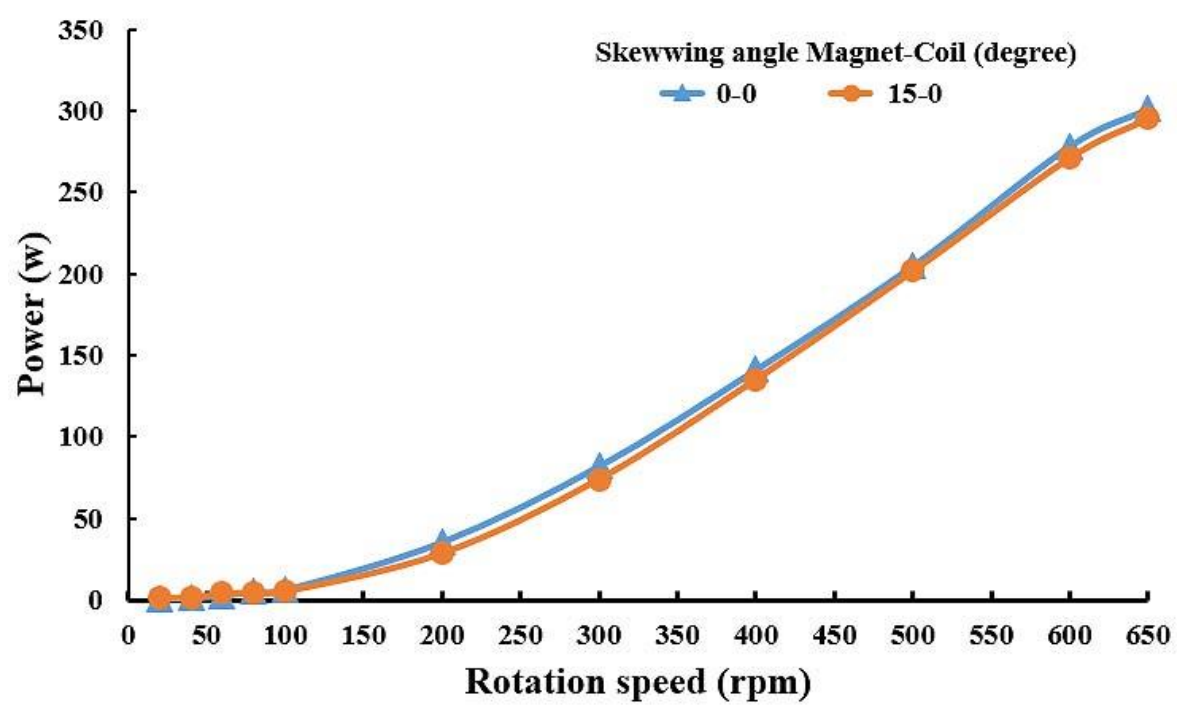

Figure 8: The comparison of the 0-0 and 15-0 degree skewing angle magnet-coil conditions based on the relationship of power and rotation speed.

\section{Conclusion}

The low speed vertical wind turbine requires a novel blade and electrical generator design for a cut-in at $2 \mathrm{~m} / \mathrm{s}$. The Savonius and H-Darrieus stacked blade can be operated at a wind speed of $1.90 \mathrm{~m} / \mathrm{s}$ and torque of $1.31 \mathrm{~N}-\mathrm{m}$ under no-load. Despite the PMSG electrical generator being used, it was able to generate a high starting torque that is not typically found in

195 a low speed wind turbine. The connection of the skewing angle magnet-coil at 15-0 degree with the blade was shown to cutin at $2.1 \mathrm{~m} / \mathrm{s}$ in a fully operation vertical wind turbine. However, the skewing angle magnet-coil at $15-0$ degree is also reduced average power by $1.50 \%$ at $25-650 \mathrm{rpm}$. Therefore, the low speed vertical wind turbine requires a newly designed blade for high and low starting torque PMSG generators.

\section{Acknowledgements}

200 The work is financially supported by Electricity Generating Authority of Thailand: EGAT (61-F405000-11IO.SS03F3008347), Energy policy and planning office (EPPO) 2018; Ministry of Energy (Thailand), Wind Turbine and Energy Storage Systems Centre (WEESYC), Centre of Excellence in Materials Engineering (CEME), Prince of Songkla University. 


\section{References}

Bakiev, R. R., Schevchenko, A. F., and Babitsky, D. Y.: Methods for reducing cogging torque in permanent magnet synchronous motors, IOP Conference Series: Earth and Environmental Science, 194, 022002, 10.1088/1755$210 \quad 1315 / 194 / 2 / 022002,2018$.

Belmili, H., Cheikh, R., Smail, T., Seddaoui, N., and Biara, R. W.: Study, design and manufacturing of hybrid vertical axis Savonius wind turbine for urban architecture, Energy Procedia, 136, 330-335, https://doi.org/10.1016/j.egypro.2017.10.389, 2017.

Bianchi, N., and Bolognani, S.: Design techniques for reducing the cogging torque in surface-mounted PM motors, IEEE 215 Transactions on Industry Applications, 38, 1259-1265, 10.1109/TIA.2002.802989, 2002.

Bülow, F., Eriksson, S., and Bernhoff, H.: No-load core loss prediction of PM generator at low electrical frequency, Renewable Energy, 43, 389-392, https://doi.org/10.1016/j.renene.2011.12.002, 2012.

Suppachai, J., Montri, S., Wattana ,R., Priwan., P., and Chainuson, K.: Performance of Stacking a Darrieus-Savonius Wind Turbine for Low-Speed Operation, APHEIT Journal, 8, 64-75, 2019.

220 Cistelecan, M. V., Popescu, M., and Popescu, M.: Study of the Number of Slots/Pole Combinations for Low Speed Permanent Magnet Synchronous Generators, 2007 IEEE International Electric Machines \& Drives Conference, 2007, 1616-1620,

Dabiri, J. O.: Potential order-of-magnitude enhancement of wind farm power density via counter-rotating vertical-axis wind turbine arrays, Journal of renewable and sustainable energy, 3, 043104, 2011.

Eom, J.-B., Hwang, S.-M., Kim, T.-J., Jeong, W.-B., and Kang, B.-S.: Minimization of cogging torque in permanent magnet 225 motors by teeth pairing and magnet arc design using genetic algorithm, Journal of Magnetism and Magnetic Materials, 226230, 1229-1231, https://doi.org/10.1016/S0304-8853(01)00053-1, 2001.

Germar, M., Vogt, K., and Ponick, B.: Berechnung elektrischer maschinen, John Wiley \& Sons, 2012.

Haring, T., Forman, K., Huhtanen, T., and Zawadzki, M.: Direct drive-opening a new era in many applications, Conference Record of the 2003 Annual Pulp and Paper Industry Technical Conference, 2003., 2003, 171-179,

230 Hsieh, M. F., Dorrell, D. G., Yeh, Y. H., and Ekram, S.: Cogging torque reduction in axial flux machines for small wind turbines, 2009 35th Annual Conference of IEEE Industrial Electronics, 2009, 4435-4439,

Jiang, Y., Zhao, P., Stoesser, T., Wang, K., and Zou, L.: Experimental and numerical investigation of twin vertical axis wind turbines with a deflector, Energy Conversion and Management, 209, 112588, https://doi.org/10.1016/j.enconman.2020.112588, 2020.

235 Lateb, R., Takorabet, N., and Meibody-Tabar, F.: Effect of magnet segmentation on the cogging torque in surface-mounted permanent-magnet motors, IEEE Transactions on Magnetics, 42, 442-445, 10.1109/TMAG.2005.862756, 2006. 
Levin, N., Pugachov, V., and Orlova, S.: Direct-Drive Contactless Wind Generator with Concentrated Winding, Latvian Journal of Physics and Technical Sciences, 49, 14-20, https://doi.org/10.2478/v10047-012-0019-z, 2012.

Liu, J., Lin, H., and Zhang, J.: Review on the technical perspectives and commercial viability of vertical axis wind turbines, Ocean Engineering, 182, 608-626, https://doi.org/10.1016/j.oceaneng.2019.04.086, 2019.

Magnussen, F., and Sadarangani, C.: Winding factors and Joule losses of permanent magnet machines with concentrated windings, IEEE International Electric Machines and Drives Conference, 2003. IEMDC'03., 2003, 333-339 vol.331,

Malipeddi, A. R., and Chatterjee, D.: Influence of duct geometry on the performance of Darrieus hydroturbine, Renewable Energy, 43, 292-300, https://doi.org/10.1016/j.renene.2011.12.008, 2012.

245 Ose-Zala, B., Pugachov, V., and Levin, N.: Start-up torques of permanent magnet synchronous generator with non-overlapping concentrated windings, 2014 Electric Power Quality and Supply Reliability Conference (PQ), 2014, 195-198,

Paquette, J. A., and Barone, M. F.: Innovative offshore vertical-axis wind turbine rotor project, Sandia National Lab.(SNLNM), Albuquerque, NM (United States), 2012.

Saavedra, H., Urresty, J.-C., Riba, J.-R., and Romeral, L.: Detection of interturn faults in PMSMs with different winding configurations, Energy Conversion and Management, 79, 534-542, https://doi.org/10.1016/j.enconman.2013.12.059, 2014.

Soderlund, L., Eriksson, J., Salonen, J., Vihriala, H., and Perala, R.: A permanent-magnet generator for wind power applications, IEEE Transactions on Magnetics, 32, 2389-2392, 10.1109/20.511354, 1996.

Takao, M., Kuma, H., Maeda, T., Kamada, Y., Oki, M., and Minoda, A.: A straight-bladed vertical axis wind turbine with a directed guide vane row — Effect of guide vane geometry on the performance —, Journal of Thermal Science, 18, 54-57, 255 10.1007/s11630-009-0054-0, 2009.

Walsh, C.: Offshore Wind in Europe-key trends and statistics 2018, Wind Europe, Brussels, 2019.

Wirtayasa, K., Irasari, P., Kasim, M., Widiyanto, P., and Hikmawan, M.: Design of an axial-flux permanent-magnet generator(AFPMG) $1 \mathrm{~kW}, 220$ volt, $300 \mathrm{rpm}, 1$ phase for pico hydro power plants, 2017 International Conference on Sustainable Energy Engineering and Application (ICSEEA), 2017, 172-179,

260 Wong, K. H., Chong, W. T., Sukiman, N. L., Shiah, Y.-C., Poh, S. C., Sopian, K., and Wang, W.-C.: Experimental and simulation investigation into the effects of a flat plate deflector on vertical axis wind turbine, Energy Conversion and Management, 160, 109-125, https://doi.org/10.1016/j.enconman.2018.01.029, 2018. 